ISSN 2236-0859

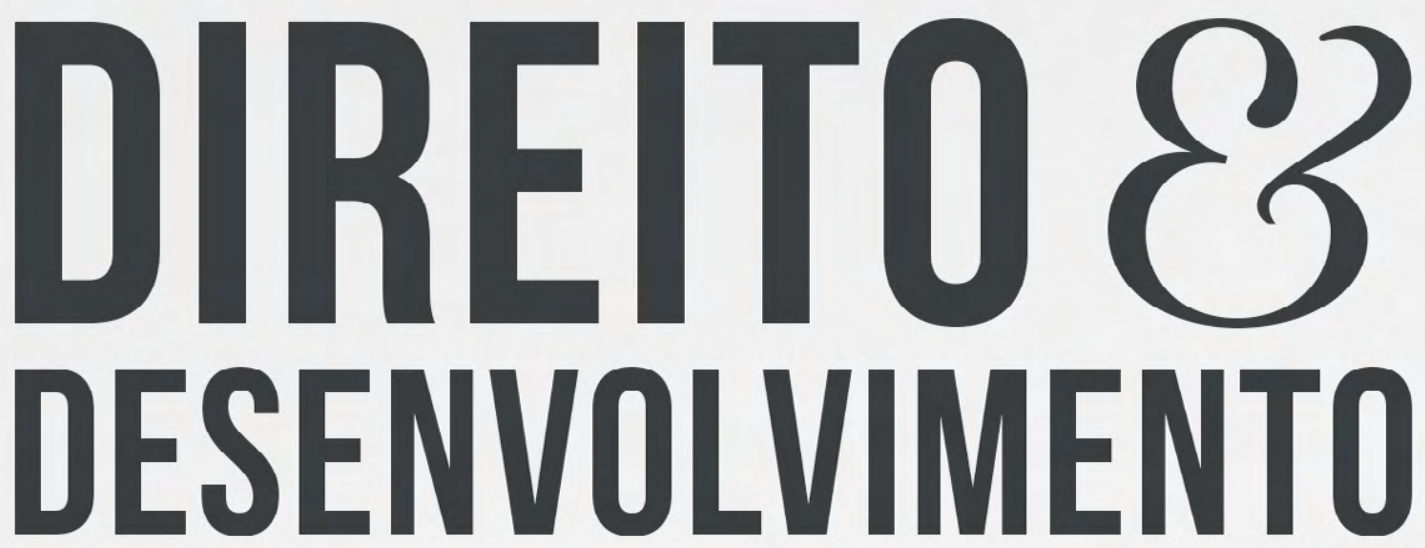

REVISTA DO PROGRAMA DE PÓS-GRADUAÇÃO EM DIREITO MESTRADO EM DIREITO E DESENVOLVIMENTO SUSTENTÁVEL

OPARADIGMA DA PROPRIEDADE PÚBLICA E PRIVADA E A NECESSIDADE DE SUA RELEITURA A PARTIRDA LEI 9.985/2000

LELLA CRISTINA DO NASCIMENTO E SILVA MARCELO KOKKE GOMES 


\title{
O PARADIGMA DA PROPRIEDADE PÚBLICA E PRIVADA E A NECESSIDADE DE SUA RELEITURA A PARTIR DA LEI 9.985/2000
}

\section{THE PARADIGM OF PUBLIC AND PRIVATE PROPERTY AND THE NEED FOR ITS REVIEW FROM LAW 9.985/ 2000}

Recebido: 05/04/2018

Aprovado: 17/05/2018
Leila Cristina do Nascimento e Silva* Marcelo Kokke Gomes**

RESUMO: A regulamentação do artigo 225, §1ํㅜㄹ inciso III da Constituição da República de 1988 pela Lei 9.985/200o que cria o Sistema de Unidades de Conservação, estabelece regime especial de tutela ambiental. Este trabalho objetiva demonstrar a necessidade de se rever os regimes de propriedade, com a quebra de paradigma entre a dicotomia público-privada. Foi utilizado o método jurídico descritivo, com pesquisa em fontes bibliográficas e legislativas sobre o tema. $\mathrm{O}$ resultado demonstra a possibilidade da convivência participativa entre ambos os regimes, sem a exclusão de um ou de outro, desde que a escolha do tipo de unidade de conservação seja efetiva e que se observe o regime de propriedade exigido por cada uma delas, e o torne decisivo.

Palavras-chave: Unidades de Conservação. Regime de Propriedade. Público. Privado. Convivência.

\begin{abstract}
The regulation of article 225, paragraph 1, item III of the Constitution of the Republic of 1988 by Law 9.985 / 2000 that creates the System of Conservation Units establishes the special regime of environmental protection. This paper aims to demonstrate the need to review property regimes and change of the paradigm between the public-private dichotomy. The descriptive legal method was used, with research on bibliographical and legislative sources on the subject. The result demonstrates the possibility of participatory coexistence between both regimes, without the exclusion of one or the other; provided that the choice of type of conservation unit should be effective and that should observe the property regime required by each case and make it decisive.
\end{abstract}

Keywords: Conservation Units. Property Regime. Public. Private. Coexistence.

\footnotetext{
* Mestre em Direito Ambiental e Desenvolvimento Sustentável pela Escola Superior Dom Helder Câmara. Especialista em ciências penais pelo IEC-PUC/MG. Especialista em Direito Ambiental pela Estácio de Sá/RJ. Analista ambiental (FEAM/MG). Membro da Comissão de Direito Ambiental da OAB-MG. E-mail: leila.crisnascimento@hotmail.com

** Pós-doutor em Direito Público - Ambiental pela Universidade de Santiago de Compostela (Espanha). Mestre e Doutor em Direito pela PUC-Rio.Especialista em processo constitucional.Procurador Federal da Advocacia-Geral da União.Professor de Direito da Escola Superior Dom Helder Câmara. Professor de Pós-graduação da PUC-MG.Professor colaborador da Escola da Advocacia-Geral da União. Professor do IDDE - MG.Membro da Associação dos Professores de Direito Ambiental do Brasil.Membro da Academia Latino Americana de Direito Ambiental. Membro do Instituto Brasileiro de Advocacia Pública. Membro da Comissão de Advocacia Pública Federal da OAB-MG. E-mail: marcelokokke@yahoo.com.br
} 


\section{INTRODUÇÃO}

O modelo de unidades de conservação americano influencia o brasileiro, fazendo com que surja no Brasil, pela primeira vez, a previsão estruturada normativamente de criação de Parques através do Decreto 23.793, de 23 de Janeiro de 1934, considerado o primeiro Código Florestal Brasileiro. O Código de 1934 considera as florestas como bem comum de uso do povo, regendo a instituição das florestas remanescentes e a concepção dos parques como ligados aos entes federativos.

A norma estabelece que o direito de propriedade seria exercido nas florestas com certas limitações. Exemplificando, observa-se a proibição de incêndios de todo o tipo, incluindo preparar o solo para a lavoura; originário da preparação de carvões; e da soltura de balões. Verifica-se a vedação de supressão de vegetação seja para a retirada desordenada de seiva, ou para o a obtenção de lenha. Veda-se também o corte de árvores que servem de habitats para animais. O Decreto 23.793/34 limita a supressão da vegetação a $3 / 4$ da reserva existente, cria uma espécie de regime de exploração de florestas em regime público e tipifica algumas infrações florestais.

O aprimoramento desse modelo perpassa pelo Código Florestal de 1965, Lei 4.771, e pela Lei 6.938/1981, que estabelece a Política Nacional do Meio Ambiente. A partir daí, a Constituição da república de 1988 dispõe no artigo 225 , §1ํㅡ, inciso III sobre a obrigação do poder público em definir os espaços territoriais a serem protegidos. Este munus é sistematizado pela Lei 9.985 , de 18 de julho de 200o, que cria o Sistema Nacional de Unidades de Conservação da Natureza- SNUC, sucedendo diplomas esparços, tal como a Lei n 6.902/81, relativa às Estações Ecológicas e Áreas de Proteção Ambiental.

A Lei do SNUC se coaduna com o compromisso firmado pelo país no plano internacional com a assinatura da Convenção da Diversidade Biológica em 1992, promulgada através do Decreto 2.519, de 16 de março de 1998. Segundo o cadastro do Ministério do Meio Ambiente (2018), calcula-se hoje a existência de 2.146 unidades de conservação no território nacional, o equivalente a aproximadamente $1.582 .861 \mathrm{Km}^{2}$, incluindo-se categorias de proteção integral e as de uso sustentável, de domínio da União, dos Estados e dos Municípios. Observa-se que o rol de unidades de conservação trazido por esta legislação não extingue a possibilidade que outras espécies de espaços protegidos sejam criadas. Será demonstrado no presente estudo que existem unidades de conservação previstas em outras legislações, que não a Lei 9.985/200o, que merecem igual tutela jurídica ambiental.

O presente artigo objetiva, a partir do método jurídico descritivo, demonstrar a importância das unidades de conservação e fazer uma análise acerca da necessidade de se reler o direito de propriedade, a fim de romper com o paradigma da propriedade pública e privada, e demonstrar como a última pode conviver com o modelo especial coletivo de propriedade exigido pela tutela ambiental.

Demonstrar-se-á a existência deste regime especialíssimo, especialmente a partir do exemplo das Reservas Particulares de Patrimônio Natural - RPPN's, nas quais, mesmo após a criação da Unidade de Conservação, a propriedade continua sendo privada. Porém, há a preservação do interesse público que se manifesta na tutela ambiental, na fiscalização e na orientação dada pelos entes públicos aos entes privados, sobretudo no que diz respeito à gestão dessas unidades. A partir do exemplo das Reservas Extrativistas, procura-se demonstrar a possibilidade da utilização de uma área pública por particulares, que se submetem a certas normas de propriedade, podendo em caso de abuso, serem destituídos do direito real de concessão de uso. O presente estudo utiliza ainda do método jurídico-exploratório partindo-se da premissa que o poder público tem o munus de efetivar a escolha do regime de implantação destas unidades, e, a partir daí, tomar as providências para que a criação destas se dê de forma efetiva, obedecendo aos procedimentos necessários em cada caso. 


\title{
2 BREVE HISTÓRICO ACERCA DAS UNIDADES DE CONSERVAÇÃO
}

A cultura da humanidade seja por motivo religioso, cultural ou de status social demonstra desde a antiguidade ser comum a preservação de espaços naturais, como se verifica na história da "Índia, da África do Sul (o povo Venda), da China, de Veneza, da Bretanha, da Rússia e da Inglaterra” (SILVA, 20o8, p. 310). A tutela das áreas protegidas está presente na legislação de quase todos os países. Pode-se destacar a criação do Parque Nacional de Yellowstone em 1872 nos Estados Unidos como inspirador do modelo de unidades de conservação existente atualmente (BENJAMIN, 2001).

Edna Cardozo Dias (2013, p. 127) escreve sobre o histórico das unidades de conservação a criação em 1890 do "Krüeger National Park, na África do Sul, cujo objetivo era garantir a proteção dos recursos naturais. A principal finalidade era recuperar a população animal. Em 1914, a Suíça estabeleceu seu primeiro parque para fins científicos.". Embora a legislação pátria sobre unidades de conservação date de 200o, observa-se que o Decreto 23.793, de 23 de janeiro de 1934 previa, ainda que de forma incipiente, a criação de parques no Brasil, o que possibilitou a criação dos parques nacionais do Itatiaia e do Iguaçu, em 1937 e 1939, respectivamente.

Porém cumpre destacar, conforme observa José Afonso da Silva, que antes mesmo da constituição destes parques, no século XIX, já se constatava a existência de alguns Jardins Botânicos e Hortos Florestais:

\begin{abstract}
A preocupação legislativa com as Unidades de Conservação surgiu com a criação dos jardins Botânicos no século passado, a começar pelo Jardim Botânico do Rio de Janeiro, criado pelo Alvará de 1.3.1811, seguido mais tarde pelos Jardins Botânicos da Bahia (1825), Cuiabá (1825), Aracaju (1825), Ouro Preto (1825), Olinda (18250 e São Luiz (1830), de alguns Hortos Florestais, criados a partir de 1910 (Gávea/RJ; Ubujara/CE; Ibura/SE; Lorena/SP) (SILVA, 2013, p. 253).
\end{abstract}

O Código Florestal de 1965, Lei 4.771/65, aprimora a previsão do Decreto de 1934, dispondo em seu artigo $5^{\circ}$, pela primeira vez, a respeito da obrigação do poder público em criar parques nacionais, estaduais e municipais e reservas biológicas visando à conciliação da proteção integral da flora, da fauna e das belezas naturais com a utilização para objetivos educacionais, recreativos e científicos. (BRASIL, 1965).

Observa-se que a Lei 6.902/1981 ao dispor sobre a criação de Estações Ecológicas e Áreas de Proteção Ambiental inicia, nas palavras de Salert e Fensterseifer (2014, p. 220), a "consolidação do regime jurídico de unidades de conservação" que temos hoje. As estações ecológicas eram criadas com finalidade científica, implantadas em áreas de domínio público ou desapropriadas, com várias restrições de uso. Já nas áreas de proteção ambiental "por envolver área de propriedade privada - e não pública como ocorre na hipótese das Estações Ecológicas -, o seu regime jurídico de proteção era menos rigoroso" (SARLET; FENSTERSEIFER, 2017, p. 221).

No mesmo ano de 1981, a Lei 6.938, Política Nacional do Meio Ambiente estabelece no artigo $2^{2}$, inciso IV, como diretriz "a proteção dos ecossistemas, com a preservação das áreas representativas" (BRASIL, 1981). Cumpre destacar que estas legislações, Leis 4.771/1965, 6.902/1981 e Lei 6.938/1981, são importantes para se iniciar no Brasil a discursão em torno do regime especial de proteção, porém não lhe garantem plena eficácia.

Em 1988, o discurso das áreas que carecem de proteção especial ganha proteção constitucional, vez que a Carta Magna dispõe que todos têm direito ao meio ambiente ecologicamente equilibrado, impondo-se ao Poder Público e à coletividade o dever de preservá-lo para as presentes e futuras gerações. A Constituição da República estabelece a obrigatoriedade de o Poder público definir em todas as unidades da Federação, espaços territoriais que merecem proteção especial, sendo a sua alteração e supressão só permitidas através de lei e vedada qualquer forma de utilização que comprometa a sua integridade (BRASIL, 1988).

Verifica-se que a proteção constitucional seleciona o meio ambiente como um bem a ser conservado e preservado para as presentes e futuras gerações. O que não significa parar o 
desenvolvimento civilizacional, mas sim, repensar os hábitos da humanidade sobre uma lógica integrativa do ser humano com o meio ambiente que habita, com a solidariedade ética para as gerações futuras. O princípio internacional da Solidariedade Intergeracional é adotado pela Constituição da República que estende a titularidade do meio ambiente "não só à coletividade presente, mas às futuras gerações. Isso importa na imposição a toda a coletividade do dever de proteger e preservar o meio ambiente, bem como de buscar a sua reparação, de forma a manter a integridade do planeta" (SILVA, 2011, p.119) O grande desafio da modernidade passa pela compatibilização do desenvolvimento sustentável com a tutela do meio ambiente.

Os Estados Americanos participaram da elaboração da Convenção para a proteção da flora, fauna e belezas cênicas dos países da América, conhecida como Convenção de Washington. A Convenção foi aprovada pelo Congresso Nacional Brasileiro por meio do Decreto Legislativo no 3, de 1948. Entretanto, a ratificação somente veio por meio do Decreto 58.054, de 23 de março de 1966. A Convenção, em seu artigo $1^{\circ}$, item 1, identifica os parques nacionais como regiões estabelecidas para a proteção e conservação das belezas cênicas naturais e da flora e fauna de importância nacional das quais o público pode aproveitar-se melhor ao serem postas sob a superintedência oficial. Observa-se que a referida Convenção prevê o estudo destes governos para a criação dos parques, e a alteração desses espaços mediante ação da autoridade legislativa (BRASIL, 1966).

Porém, pode-se afirmar que o principal documento sobre o tema no âmbito internacional só foi instituído na ECO 1992 com a assinatura da Convenção de Diversidade Biológica (DIAS, 2013). Este documento estabelece a obrigação das partes em estabelecer um sistema de áreas protegidas ou espaços onde medidas especiais precisam ser tomadas para conservar a diversidade biológica. Segundo a CDB áreas protegidas são definidas geograficamente, destinadas, ou regulamentadas, e administradas para alcançarem objetivos específicos de conservação (BRASIL, 1994).

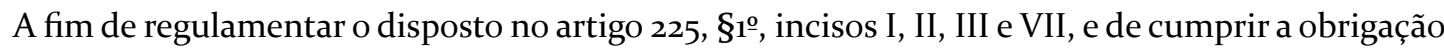
assumida na CDB, foi estabelecido no ano 200o, o Sistema Nacional de Unidades de Conservação da Natureza, Lei 9.985 , de 18 de julho de 2000 , também conhecida como lei do SNUC. É naquele contexto político internacional que se situa o diploma.

\footnotetext{
Neste cenário histórico-evolutivo da legislação ambiental brasileira, a Lei 9.985/200o, ao regulamentar os incisos I, II, II e VII do §1º do art. $225 \mathrm{da} \mathrm{CF} / 88$, representa o aprimoramento e sistematização do regime jurídico de proteção de áreas ambientais. Mantendo forte relação com outros institutos jurídicos-ambientais, como é o caso das áreas de preservação permanente e da reserva legal, as unidades de conservação constituem um dos mais importantes instrumentos de proteção dos nossos recursos naturais, em especial de fragmentos dos biomas tidos como patrimônio nacional pelo art. 225, § $4^{\circ}$, da $\mathrm{CF} / 88$, notadamente a Floresta Amazônica brasileira, a Mata Atlântica, a Serra do Mar, o Pantanal Mato-Grossense e a Zona Costeira (SARLET; FENSTERSEIFER, 2014, p. 262).
}

Antônio Herman de Vasconcellos e Benjamin (2001) critica o fato dea legislação infraconstitucional utilizar a terminologia unidades de conservação ao invés de espaços territoriais especialmente protegidos conforme faz a Constituição da República e a CDB. A segunda terminologia seria para ele mais apropriada por traduzir a ideia de proteção integral, sendo a unidade de conservação uma espécie deste gênero, e não o contrário.

A Lei 9.985/oo prevê as categorias de unidades de conservação de proteção integral e de uso sustentável. Nos termos do artigo 8o do referido diploma legal, o grupo das unidades de conservação de proteção integral é composto por Estação Ecológica, Reserva Biológica, Parque Nacional, Monumento Nacional e Refúgio da Vida Silvestre, e objetivam a preservação ambiental, sendo permitido em regra, apenas seu uso indireto.

Já o conjunto das unidades de uso sustentável é composto por Áreas de Proteção Ambiental, Área de Relevante Interesse Ecológico, Floresta Nacional, Reserva Extrativista, Reserva de Fauna, Reserva de 
Desenvolvimento Sustentável e Reserva Particular do Patrimônio Natural. Nestas unidades o objetivo é compatibilizar o uso dos seus recursos com a preservação da natureza (BRASIL, 200o).

Para Herman Benjamin as unidades de conservação previstas na lei do SNUC são consideradas típicas. Existem ainda as atípicas, esparsas no ordenamento brasileiro e que não fazem parte do Sistema Nacional das Unidades de Conservação, "cabendo citar, dentre tantas, as Áreas de Preservação Permanente, a Reserva Legal, a Reserva da Biosfera, as Áreas de Servidão Florestal, a Reserva Ecológica, os monumentos naturais tombados e as Reservas Indígenas" (BENJAMIN, 2001, p. 27).

\section{ALGUNS ASPECTOS SOBRE O REGIME ESPECIAL DAS UNIDADES DE CONSERVAÇÃO E A QUEBRA DE PARADIGMA POR ELE PROPOSTA}

O artigo $2^{\circ}$, inciso I da Lei 9.985/200o, define unidade de conservação como "o espaço territorial e seus recursos ambientais, incluindo as águas jurisdicionais, com características naturais relevantes, legalmente instituído pelo Poder Público, com objetivos de conservação e limites definidos, sob regime especial de administração, ao qual se aplicam garantias adequadas de proteção" (BRASIL, 200o).

A criação de unidades de conservação tem por objetivo maior eficácia na manutenção da biodiversidade, porém há outros vários aspectos de sua relevância, como mitigação do efeito estufa; garantia da quantidade e da qualidade dos recursos hídricos; assegurar a produção de energia elétrica (vez que no Brasil grande parte das hidroelétricas se encontram localizadas à jusante das unidades de conservação) e possibilita a conservação da paisagem cênica (importante para o turismo nacional), dentre outros (MEDEIROS et al, 2011).

O Sistema Nacional de Unidades de Conservação tem ainda por objetivos a preservação de espécies; a conservação da natureza e a proteção dos recursos genéticos; a proteção dos ecossistemas e a manutenção de recursos essenciais para a subsistência de populações tradicionais. Porém, pode-se destacar que o artigo $4^{\circ}$ da Lei do SNUC também ressalta, dentre os seus objetivos, a promoção da pesquisa e do desenvolvimento sustentável, através dos recursos naturais. Considera ainda a necessidade da valorização econômica e social da diversidade biológica.

Parte-se então a indagação de como seria possível conciliar o desenvolvimento com a preservação das Unidades de Conservação ou, sendo mais específico, como poderia a propriedade privada conviver com este modelo?

O direito à propriedade nasce como um direito individual, considerando os ideais burgueses insculpidos pela Revolução Francesa, considerando que o Estado não deveria intervir nas relações dos indivíduos. Este modelo de Estado Liberal, que surge no século XVII, integra-se ao capitalismo, em que a propriedade é sinônimo de status, atingindo, sobretudo, os bens corpóreos (LACERDA, et al, 2014).

Ocorre que, nos séculos XIX e XX, surge a necessidade de se tutelar os bens incorpóreos e "as mudanças sociais passaram a influenciar sobremaneira os caracteres da propriedade, levando a evolução do absolutismo individual à noção de função social" (LACERDA, et al, 2014, p. 1198).

Já a sociedade moderna exige uma releitura do direito de propriedade, considerando o que se chama de sustentabilidade, incluindo-se nesta categoria o direito ao meio ambiente equilibrado como um direito difuso, de todos. Nessa perspectiva, a Constituição da República de 1988 estabelece, como um dos princípios do direito da propriedade, a sua função ecológica, sobretudo quando, no artigo 186 dispõe que a função social da propriedade será cumprida quando houver a utilização adequada dos recursos naturais disponíveis e a preservação do meio ambiente (BRASIL, 1988).

Desta forma, observa-se a necessidade de se haver uma quebra de paradigma da propriedade individual para uma percepção de efeitos coletivos, e essencialmente da dicotomia entre público e privado. "A construção político-jurídica denominada Estado Constitucional Moderno é insuficiente para o atual momento em que vive a civilização humana na terra" (CRUZ; SIRVENT, 2006, p.43). 
Para Pilat (2009) essa releitura não implica necessariamente no descarte da previsão legal insculpida no artigo 1.228 do Código Civil. Significa a necessidade de convivência de dois modelos: o civilista, em que a propriedade é fundada no uso, gozo e disposição da coisa, bem como no direito de reivindica-la e o segundo modelo das propriedades especiais constitucionais. $\mathrm{O}$ autor escreve que:

Se a modernidade apropriou-se do coletivo em favor do particular, a pós modernidade não pode ir para o outro extremo: anular o particular num coletivo de feição estatal. Pois tal tese chega, por linha transversa e ironicamente ao mesmo resultado que combate, porque desagua num coletivo autocrático, com a mesma feição da modernidade. A pósmodernidade deverá instituir um sistema estruturado na tríplice dimensão que Roma ensinou: de coletivo X privado X estatal (PILAT, 2009, p.95).

O próprio artigo 1.228 do Código Civil estabelece, em seu parágrafo $1^{\circ}$, que o direito de propriedade deve ser exercido em consonância com as suas finalidades econômicas e sociais e de forma a preservar a flora, a fauna, as belezas naturais, o equilíbrio ecológico, o patrimônio histórico e artístico, devendo ser evitada a poluição do ar e das águas. Observa-se que este regime privado corpóreo de propriedade assume esta função social e convive com o regime público de propriedade insculpido no Direito Administrativo.

As unidades de conservação podem ser de domínio público ou privado. Dentre as unidades de conservação consideradas típicas, ou seja, pertencentes à Lei do SNUC, serão necessariamente de titularidade pública a Estação Ecológica, a Reserva Biológica, o Parque Nacional, a Floresta Nacional, a Reserva Extrativista e a Reserva de Fauna. As demais unidades permitiram que o domínio seja todo privado ou a convivência dos dois regimes.

Dessa forma, o conceito de propriedade pública ou privada não se faz suficiente, havendo a necessidade da convivência e do equilíbrio com o sistema de propriedade especial constitucional, estando, em matéria ambiental, regulado pela lei do Sistema das Unidades de Conservação. Na verdade, ao se estabelecer a necessidade da tutela ambiental para os presentes e as futuras gerações como se verifica no artigo 225 da Carta Magna, faz-se necessário uma releitura do conceito de propriedade com a inserção do indivíduo na democracia participativa. O indivíduo participa da questão ambiental e busca com os demais um consenso em que a propriedade possa conviver com a sustentabilidade ambiental. Para Cruz e Sirvent:

A Democracia é (ou pode ser, quando funciona) um grande processo de aprendizagem coletivo e, por isso, é precisamente o único caminho com o qual se pode esperar chegar à sustentabilidade. A nova cultura da sustentabilidade deve caracterizar-se, como a Democracia, por uma base de entendimento comum (algumas práticas sociais, alguns valores, alguns critérios de juízo socialmente compartilhados) que representem o mínimo indispensável para fazer convergir o interesse político e social na direção da sustentabilidade ambiental, e deixar em aberto o máximo de espaço possível às diferenças entre as ideias e suas interações. Ou seja, de tal maneira que possam conviver dialeticamente diversas hipóteses de sociedade sustentável (CRUZ; SIRVENT, p. 50).

Os Estados, em ambiente de preocupação global com a questão ambiental, assinam tratados internacionais, sobretudo com o objetivo de cooperação entre as nações em prol da manutenção das condições de vida no planeta. Ao assinar esses documentos têm a sua capacidade de decisão restringida, devendo obedecer às diretrizes destes tratados. Pode-se afirmar que o Estado abre mão de parcela de sua soberania para participar de entidades políticas internacionais mais complexas. Não se trata de competição entre nações soberanas, mas da conjugação de esforços em prol do objetivo comum.

A Constituição da República de 1988 considera a função social da propriedade e a defesa do meio ambiente como um dos postulados da ordem econômica o que torna necessária uma modelação das "vantagens individuais e privadas do proprietário e os benefícios sociais e ambientais, referentes ao proveito coletivo" (LACERDA, et al, 1201).

Nos casos em que, após a criação da unidade de conservação, a propriedade continua sendo privada, a jurisprudência afirma que há uma limitação administrativa ao direito de propriedade e não 
a necessidade de desapropriação. A propriedade permanecerá privada, ainda que haja algum prejuízo econômico para o proprietário. Será admitida a desapropriação apenas em caso de total esvaziamento econômico da propriedade, com total apossamento pelo poder público. É o que se depreende do Agravo Regimental no Agravo em Recurso Especial de número 155302/RJ:

A criação de áreas especiais de proteção ambiental - salvo quando tratar-se de algumas unidades de conservação de proteção de proteção integral e de uso sustentável em que a lei impõe que o domínio seja público -configura limitação administrativa, que se distingue da desapropriação. Nesta, há transferência da propriedade individual para o domínio do expropriante com integral indenização; naquela, há apenas restrição ao uso da propriedade imposta genericamente a todos os proprietários, sem qualquer indenização (BRASIL, 2012, p. 1).

A propriedade especial constitucional parte de uma relativização do indivíduo como proprietário e da inclusão de entidades e relações jurídicas coletivas como objeto de tutela. Conforme explica Pilati (2009), isso envolve um pluralismo de fontes, em que a norma constitucional conviva com a legislação civilista individualista e com a legislação especial. O autor classifica as propriedades especiais em particulares, público-privadas e coletivas.

Dentre as propriedades especiais particulares destacam-se as Reservas Particulares do Patrimônio Natural- RPPN's. Essas propriedades serão assim declaradas pela intenção do proprietário que irá provocar o poder público a se manifestar a respeito do interesse público da área nos termos do Decreto 5.746, de 5 de abril de 2006. Essa manifestação do poder público deve ser inequívoca, atendendo-se ao oficialismo, seu pressuposto formal jurídico (BENJAMIN, 2001). O proprietário efetiva junto ao órgão ambiental termo de compromisso de conservação da área, que será averbado no registro público de imóveis.

Observa-se que o proprietário continua tendo o direito de inclusive dispor do imóvel, porém, o seu uso deve se dar de forma sustentável sendo permitido tão somente a pesquisa científica e a visitação com objetivos turísticos, recreativos e educacionais nos termos do artigo 21 da Lei do SNUC (BRASIL, 200o). Há interesse público na conservação das RPPN's, quando são "identificadas condições naturais primitivas, semiprimitivas, recuperadas ou cujas características justifiquem ações de recuperação, pelo seu aspecto paisagístico, ou para a preservação do ciclo biológico de espécies da fauna ou da flora nativa do Brasil" (SILVA, 2013, p. 271). Porém o modelo repudia a desapropriação dos espações protegidos, permanecendo a titularidade privada. O poder público continua investido de poderes para prestar auxílio técnico e científico ao proprietário da RPPN, para a gestão e confecção do plano de manejo destas unidades, nos termos do artigo 21, § $3^{\circ}$, da Lei 9.985/oo, o que faz do modelo híbrido, especial, a nosso ver.

O plano de manejo ou o plano de proteção e de gestão, elaborados pelo particular com a orientação do poder público, são documentos técnicos que estabelecem os objetivos gerais da unidade de conservação, traçando o zoneamento e as normas que devem ser seguidas para a utilização dos recursos naturais existentes na unidade. Diz também respeito às instalações físicas a serem edificadas para que a finalidade precípua de proteção seja alcançada. A criação das RPPN's ocorre por ato voluntário de particulares, a área passa a ser gravado com perpetuidade, a partir da sua instituição, o que garante certa segurança com relação à proteção ambiental a ela conferida.

O Ministério Público Federal ajuizou, nos termos da apelação civil pública no 45-33.2005.4.03.6103/ SP, ação contra a Companhia de Saneamento do Estado de São Paulo - SABESP, a Fazenda Pública do Estado de São Paulo e contra o Instituto Brasileiro do Meio Ambiente e dos Recursos Naturais Renováveis - IBAMA, a fim de proteger área de vegetação de Mata Atlântica, floresta ombrófila densa em estágio avançado. Observa-se no caso que a SABESP já havia obtido licença prévia e de instalação para a construção de uma barragem e obras de captação tratamento e distribuição de água em área de propriedade particular em Barra do Uma, distrito de Maresias, município de São Sebastião, no litoral norte de São Paulo. Verifica- 
se que após a obtenção das licenças e da autorização de corte pelos órgãos ambientais e da anuência do IBAMA, a área foi reconhecida como RPPN Rizzieri, o que fez com que os proprietários da área solicitassem a revogação do decreto que instituiu a área como de utilidade pública para fins de desapropriação ou servidão administrativa em favor da SABESP (BRASIL, 2013).

Foi considerada a incompatibilidade da obra de utilidade pública pretendida pelo poder público com a proteção ambiental do Bioma Mata Atlântica. A RPPN só permite, nos termos do artigo 21 da Lei 9.985/oo, a sua utilização para a pesquisa científica e visitação para afins turísticos, educacionais e recreativos. A interferência nessa unidade por utilidade pública ou interesse social só seria permitida, nos termos do artigo 36 e 46 da Lei do SNUC, se precedida de análise através de estudo de impacto ambiental- EIA/RIMA. Desta forma, em sede da apelação foram consideradas nulas as licenças ambientais e anuências concedidas para o empreendimento. Com a exigência de ser realizado o EIA/RIMA do local, englobando estudo de alternativas locacionais fora da RPPN Rizzieri "por serem excepcionais as possibilidades de intervenções em área de vegetação secundária em estágio avançado de regeneração integrante do bioma mata atlântica, sob pena de multa diária no valor de $\mathrm{R} \$ 50.000$,oo (cinquenta mil reais), nos termos do art. 11 da Lei no 7.347/85" (BRASIL, 2013, s/p).Exemplo de propriedade especial de uso coletivo são as reservas extrativistas, que nos termos do artigo 18 da Lei do Sistema Nacional de Unidades de Conservação são áreas utilizadas pelas populações tradicionais que vivem da extração de recursos da natureza, de animais de pequeno porte, da agricultura de subsistência. Para Antunes (2014), essas reservas surgem como fruto da preservação dos seringueiros da Amazônia e objetivam a preservação do modo de vida das populações, a quem é concedido o direito real de uso destas áreas, cujo domínio permanece público. Importa salientar que é admitida a visitação pública bem como a pesquisa científica.

A concessão do direito real de uso é regulada pelo Decreto-Lei no 271, de 28 de fevereiro de 1967 e Lei n. 9.636/98. O que se protege é o modo de vida dessas populações, que podem até transmitir este direito via hereditária. Mas não se admite a transferência a terceiros, o que torna estas áreas especiais, segundo Pilati (2009). Não se pode usar da concessão para fazer com que se desvirtue a sua finalidade, não sendo permitido comercialização predatória por terceiros de produtos advindos desta propriedade ou degradação total do meio ambiente.

Desta forma, a extração não pode ser indiscriminada. Caso interessante que exemplifica a degradação do meio ambiente, ocorreu no município de Florianópolis, em que diversas famílias invadiram uma reserva extrativista da marinha, chamada de Pirajubaé. De acordo com a Apelação no 5016387-62.2015.4.04.7200/SC o município fora condenado, juntamente com outros particulares, a destruir o calçamento que estava sendo feito na região e também por omissão fiscalizatória. O município chegou a fornecer materiais para que as famílias construíssem no manguezal, porém sua ocupação ilegal trazia prejuízos ao meio ambiente, causando danos à flora e a fauna, bem como ao patrimônio paisagístico da localidade. Ao município foi imputada a responsabilidade objetiva, nos termos do artigo 37, §6o da $\mathrm{CF} / 88$, pelos danos ambientais diretos e indiretos causados na região. A FLORAM, Fundação Municipal do Meio Ambiente de Florianópolis respondeu solidariamente com o município pelos prejuízos causados, pois era o órgão competente para se proceder o licenciamento e o planejamento urbanístico da região. Os Entes públicos, além de terem que destruir as construções realizadas no local, procedendo-se a recuperação da área degradada, tiveram ainda de promover a realocação das famílias envolvidas neste incidente (BRASIL, 2017). O que se permite não é a degradação ambiental indiscriminada, ou ocupações irregulares, mas que as populações extraiam os produtos da área preservada para a sua subsistência, ou que comercializem estes produtos para que comprem outros também necessários para a garantia da sua qualidade de vida, com observação das normas ambientais vigentes e obediência ao Plano de Utilização aprovado pelo órgão gestor da unidade de conservação. Salienta-se que, caso sobrevenha o interesse público em desocupar a área, estas populações serão realocadas, em área de comum acordo, fazendo jus a receberem a indenização 
pelas benfeitorias úteis e necessárias realizadas no imóvel público em que viviam, aplicando-se as regras para indenização possessória da legislação civilista (BENATTI, 1998). Importa ressaltar que caso a Unidade de Conservação seja de titularidade pública faz-se necessário que a desapropriação do imóvel se dê de forma efetiva, e não seja declarada sua formalização por simples ato de criação.

Há a necessidade de se fazer a regularização fundiária e de se criar o plano de manejo nas as unidades de conservação, pois caso contrário incorre-se no risco de que a finalidade de preservação ou socioambiental não seja atingida. Nesse sentido destaca-se o estudo de Marcon (2004) que analisa o relatório do Tribunal de Contas da União sobre o tema:

Possuímos, na teoria, $17,5 \%$ do território nacional protegido por Unidades de Conservação. Isso seria digno de comemoração, se não fosse o estado deplorável em que esses espaços se encontram. Em recente auditoria apresentada em novembro de 2013 pelo Tribunal de Contas da União, tendo por objeto de estudo as 247 Unidades de Conservação instituídas no Bioma Amazônia (140 estaduais e 107 federais), totalizando 1,1 milhões de $\mathrm{km}^{2}$, representando $80 \%$ do total das Unidades de Conservação federais instituídas em todo o país, constatou-se que apenas $4 \%$ desses territórios estão com alto grau de implementação e gestão que permitam o cumprimento pleno dos objetivos das Unidades. Outro dado alarmante é que somente $40 \%$ desses espaços possuem plano de manejo, ferramenta essencial para a gestão, uso e consecução das finalidades das Unidades de Conservação (MARCON, 2014, p. 186).

Essa irregularidade é diferente da situação de unidades de conservação particulares ou mistas em que os dois regimes público e privado convivem formalmente. Nas RPPN's, por exemplo, que são por excelência privadas, o poder público estaria formalmente legitimado a auxiliar na fiscalização da área, mas a gestão incumbiria ao seu proprietário. No modelo misto, como ocorre, por exemplo, com as Áreas de Proteção Ambiental, e com as áreas de relevante interesse ecológico, há restrições à propriedade privada, mas a instituição de conselho de administração possibilita conciliar o interesse privado e público em uma mesma área, e há a permissão formal que a gestão se dê de forma compartilhada.

Entende-se que cabe ao poder público, verificada a necessidade de criação de unidade de conservação, agir de forma a escolher a melhor espécie de unidade a ser implementada, esta afirmativa decorre da leitura do artigo 225, §1º, III. Cumpre ressaltar que "o ato formal de instituição não se confunde com a criação de uma Unidade de Conservação, sendo apenas uma das etapas de todo o procedimento" (MARCON, 2014, p. 193). Ao poder público cabe a escolha do tipo da unidade, se de proteção integral ou de uso sustentável, enquadrando-se em cada caso, o regime público, privado ou misto. Entende-se que caso a escolha recaia no regime público de domínio, faz-se necessário que a desapropriação se dê de forma efetiva com justa indenização. É o que afirma Paulo de Bessa Antunes:

Infelizmente, tem sido prática muito comum que entes públicos decretem a "criação" de parques - nas três esferas de poder - e não implementem as medidas necessárias para a real constituição de unidades de conservação, muito embora desenvolvam atividades administrativas como se, de fato, as áreas tivessem sido desapropriadas e o domínio privado houvesse sido transferido para o público. Assim, são estabelecidas proibições para as atividades particulares que ultrapassam os limites do artigo 22-A da Lei do SNUC, praticando um "desapossamento branco" dos proprietários. A medida é certamente, ilegal e se caracteriza como abuso de poder ou de autoridade conforme o caso (ANTUNES, 2014, p. 908).

Sendo permitido a convivência da propriedade privada no tipo de unidade escolhido, pode-se afirmar que é um dever do poder público se articular com os particulares para que a gestão se dê de forma compartilhada com a efetiva implementação do plano de manejo. De acordo com Paulo de Bessa Antunes (2014) a criação deste instrumento de gestão é uma prerrogativa do poder público, que estabelecerá os objetivos gerais da unidade de conservação, seu zoneamento bem como suas normas internas e os recursos 
necessários para a sua efetivação. E ainda, que, seja escolhido o regime de propriedade privada, faz-se necessário o apoio dos órgãos ambientais fornecendo instruções para a sua gestão, bem como que o poder público proceda a fiscalização destas unidades.

\section{CONSIDERAÇÕES FINAIS}

O regime das unidades de conservação que, em linhas gerais, objetiva a proteção, a preservação e a conservação dos ecossistemas, ganha importância com a promulgação da Constituição da República de 1988, que em seu artigo 225, $\S^{\circ}{ }^{\circ}$, inciso III, estabelece como um dos deveres do poder público a definição dos espaços especialmente protegidos. Dessa forma, consiste em uma das obrigações do poder público sua definição de área. A regulamentação feita pela Lei do Sistema Nacional de Unidades de Conservação, Lei 9.985/200o, vai ao encontro do compromisso firmado pelo Brasil na CDB - Convenção da Diversidade Biológica de1992.

Estas normas, se interpretadas conjuntamente, criam um regime especial de proteção dos espaços ambientalmente protegidos. Ocorre que, o direito de propriedade individual, como um ideal burguês de tutela de bens corpóreos, faz-se insuficiente diante desta especialidade.

A sociedade moderna exige uma quebra de paradigma da propriedade incluindo-se na dicotomia público-privada a necessidade de se preservar bens incorpóreos de natureza difusa, como o meio ambiente. Conclui-se que a proposição desta releitura não descarta a propriedade civilista, prevista no artigo 1228 do Código Civil. Trata-se de promover a conciliação dos regimes públicos e privados reconhecendo a insuficiência destes sistemas per si para a tutela ambiental.

Ficou demonstrado que a convivência da titularidade privada com o auxílio técnico, científico e fiscalizatório do poder público na gestão destas unidades é possível (como ocorre com as RPPN's). Demonstrou-se ainda a viabilidade da opção inversa: a titularidade pública das áreas protegidas conviver com a concessão privada ao direito de uso, como no caso das Reservas Extrativistas, utilizadas pelas populações tradicionais, que devem respeitar certas restrições ao referido direito real. Por fim, observouse que ao criar as Unidades de Conservação, o poder público deve escolher o tipo de espaço protegido que melhor se enquadra à real necessidade da tutela ambiental e fazer de tudo para que o regime de propriedade se adeque à sua escolha.

Assim, se o tipo de área protegida exigir a tutela integralmente pública, faz-se necessário que ocorra a efetiva desapropriação, com justas indenizações. O que não deve ocorrer é a irregularidade fundiária com a criação de unidades de conservação apenas sobre o aspecto formal, pois isso ensejaria um ônus excessivo aos particulares.

A coexistência de propriedades públicas e privadas em uma mesma área necessita da constituição de um conselho de administração e da efetiva implementação de plano de manejo com previsão de gestão co-participativa de entes públicos e privados. A criação das UC's para ser efetiva deve criar embaraços à degradação ambiental de forma a promover a preservação ambiental para as presentes e futuras gerações.

\section{REFERÊNCIAS}

ANTUNES, Paulo de Bessa. Direito Ambiental. 16. ed. São Paulo: Atlas, 2014.

BENATTI, José Heder. A criação de unidades de conservação em áreas de apossamento de populações tradicionais: um problema agrário ou ambiental? Periódicos UFPA, Belém, v.1, n.2, 1998. Disponível em: <http://repositorio.ufpa.br/jspui/bitstream/2011/3076/1/Artigo_CriacaoUnidadesConservacao.pdf> Acesso em: 07 ago. 2017. 
BENJAMIN, Antonio Herman de Vasconcellos e. O regime brasileiro de unidades de conservação. Revista de Direito Ambiental, São Paulo, v. 6, n. 21, p. 27-56, jan./ mar. 2001. Disponível em: <http://bdjur.stj.jus. br/dspace/handle/2011/279o6> Acesso em: 11 jul. 2017.

BRASIL. Constituição (1988). Constituição da República Federativa do Brasil. Brasília, DF: Senado Federal, Centro Gráfico, 292p, 1988.

Decreto-Lei no 23.793, de 23 de janeiro de 1934. Aprova o código florestal que com este baixa. Diário Oficial, Brasília, 21 mar. 1934.

Decreto-Lei no 58.054, de 23 de março de 1966. Promulga a Convenção para a proteção da flora, fauna e das belezas cênicas dos países da América. Diário Oficial, Brasília, 30 mar 1966.

Decreto-Lei no 4.771, de 15 de setembro de 1965. Institui o novo Código Florestal. Diário Oficial, Brasília, 16 set. 1965 .

Decreto-Lei no 6.902, de 27 de abril de 1981. Dispõe sobre a criação de Estações Ecológicas, Áreas de Proteção Ambiental e dá outras providências. Diário Oficial, Brasília, 28 abr. 1981.

Decreto-Lei no 6.938, de 31 de agosto de 1981. Dispõe sobre a Política nacional do Meio Ambiente, seus fins e mecanismos de formulação e aplicação, e dá outras providências. Diário Oficial, Brasília, 2 set. 1981.

Lei no 02, de 03 de fevereiro de 1994. Aprova o texto da Convenção sobre Diversidade Biológica, assinada durante a Conferência das Nações Unidas sobre Meio Ambiente e Desenvolvimento, realizada na Cidade do Rio de Janeiro, no período de 5 a 14 de junho de 1992. Diário Oficial, Brasília, 4 fev. 1994.

Lei no 5746 , de 5 de abril de 2006. Regulamenta o artigo 21 da Lei no 9.985, de 18 de julho de 200o, que dispõe sobre o Sistema Nacional de Unidades de Conservação da Natureza. Diário Oficial, Brasília, o6 abr. 2006.

Lei no 9.985, de 18 de julho de 2000. Regulamenta o art. 225, § 10, incisos I, II, III e VII da Constituição Federal, institui o Sistema Nacional de Unidades de Conservação da Natureza e dá outras providências. Diário Oficial, Brasília, 18 jul. 2000.

Lei no 10.406, de 10 de janeiro de 2002. Institui o Código Civil. Diário Oficial, Brasília, 11 jan. 2002.

Superior Tribunal de Justiça. Agravo Regimental no Agravo em Recurso Especial 155302/RJ. Relator: Humberto Martins. Diário de Justiça Eletrônico, 20 de novembro de 2012. Disponível em: < https:// ww2.stj.jus.br/processo/revista/documento/mediado/?componente=ITA\&sequencial=1193893\&num_ registro $=201200660457 \&$ data $=20121120 \&$ formato $=\mathrm{PDF}>$ Acesso em: 09. mai.2018.

Tribunal Regional Federal da 3롤 Região. Apelação Cível no ooooo45-33.2005·4.03.6103/SP. Relator: Juiz Federal Convocado Herbert de Bruyn. Diário Eletrônico, o5 de agosto de 2013. Disponível em: <http://web.trf3.jus.br/acordaos/Acordao/BuscarDocumentoGedpro/2370052> Acesso em: 11 mai. 2018.

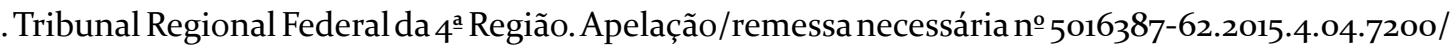
SC. Relatora: Des. Federal Vânia Hack de Almeida. Diário Eletrônico, 23 de agosto de 2017. Disponível em: <https://jurisprudencia.trf4.jus.br/pesquisa/inteiro_teor. php> Acesso em: 10 mai. 2018. 
CRUZ, Paulo Márcio; SIRVENT, José Francisco Chofre. Ensaio sobre a necessidade de uma teoria para a superação democrática do Estado Constitucional Moderno. Revista Novos Estudos Jurídicos, Itajaí, v.11, n.1, p. 41-62, jan/jun. 2006. Disponível em: <https://siaiap32.univali.br/seer/index.php/nej/article/ view/421/363> Acesso em: 03 ago. 2017.

DIAS, Edna Cardozo. Direito Ambiental no Estado Democrático de Direito. Belo Horizonte: Fórum, 2013.

LACERDA, Emanuela Cristina Andrade; ROSA, Alexandre Morais da; FERRER, Gabriel Real. A propriedade ante o novo paradigma do Estado Constitucional Moderno: a sustentabilidade. Revista Novos Estudos Jurídicos, Itajaí, v.19, n. 4, p.1185-1219, 2014. Disponível em: <https://siaiap32.univali.br//seer/index.php/ nej/article/view/6703> Acesso em: 03 ago. 2017.

MARCON, Vitor Trevelin Benatti. A vinculação do poder público na criação de unidades de conservação. Veredas do Direito, Belo Horizonte, v. 11, n. 22, p. 175-198, Jul/dez. 2014. Disponível em: <http://www. domhelder.edu.br/revista/index.php/veredas/article/view/448> Acesso em: 08 ago. 2017.

MEDEIROS, Rodrigo et al. Contribuição das unidades de conservação brasileiras para a economia nacional: Sumário Executivo. Brasília: UNEP-WCMC, 2011. Disponível em: <http://www.icmbio.gov.br/ portal/images/stories/comunicacao/estudocontribuicao.pdf> Acesso em: o9 mai. 2018.

MINISTÉRIO DO MEIO AMBIENTE - MMA. Tabela Consolidada das Unidades de Conservação. Brasília: Ministério do Meio Ambiente, 2018. Disponível em: <http://www.mma.gov.br/images/ arquivo/80238/CNUC_FEV18\%20-\%2oB_Cat.pdf>> Acesso em: o9 mai. 2018.

PILAT, José Isaac. Conceito e classificação da propriedade na pós-modernidade: a era das propriedades especiais. Revista Sequência, Florianópolis, v. 30, no 59, p. 89-119, dez. 2009. Disponível em: <https:// periodicos.ufsc.br/index.php/sequencia/article/view/21777055.2009v3on59p89/13591> Acesso em: o9 mai.2018.

SARLET, Ingo Wolfgang; FENSTERSEIFER, Tiago. Direito Ambiental: introdução, fundamentos e teoria geral. São Paulo: Saraiva, 2014.

SILVA, José Irivaldo Alves de Oliveira. As Unidades de Conservação, conforme a Lei 9.985/2000: suas características e regime jurídico-ambientais. Revista Direito e Liberdade, Mossoró, v.8, n. 1, p. 309 334, Jan/Jun. 2008. Disponível em: <http://www.esmarn.tjrn.jus.br/revistas/index.php/revista_direito_e_ liberdade/article/view/38/30> Acesso em: 09 mai.2018.

SILVA, Marcela Vitoriano e. O princípio da solidariedade intergeracional: um olhar do direito para o futuro. Veredas do Direito, Belo Horizonte, v. 8, n. 16, p. 115-146, Jul/dez. 2011. Disponível em: <http:// www.domhelder.edu.br/revista/index.php/veredas/article/viewFile/179/188> Acesso em: 13 set. 2017.

SILVA, José Afonso da. Direito Ambiental Constitucional. 1o. ed. São Paulo: Malheiros, 2013. 